\title{
Financial Intermediation and Equity Investment with Costly Monitoring
}

\author{
Giorgio Di Giorgio* \\ Università degli Studi di Roma "La Sapienza" \\ and Università "Luiss Guido Carli”
}

September 1999

\begin{abstract}
This paper studies the efficiency of equilibria in a productive OLG economy where the process of financial intermediation is characterized by costly state verification. Both competitive equilibria and Constrained Pareto Optimal allocations are characterized. It is shown that market outcomes can be socially inefficient, even when a weaker notion than Pareto optimality is considered.
\end{abstract}

Keywords: Financial Intermediation, Costly State Verification, Constrained Pareto Optimality.

J.E.L. Classification Numbers: E44, E62.

\footnotetext{
*Correspondence: Giorgio Di Giorgio, Dipartimento di Economia Pubblica, Università La Sapienza di Roma, Via del Castro Laurenziano 9, 00161, Roma, Italy. Tel. 39-06 4976 6362, Fax: 39-06-4461964.

Email: digiorg@dep.eco.uniroma1.it
} 


\section{Financial Intermediation and Equity Investment with Costly Monitoring ${ }^{\circ}$}

\section{Introduction}

As is well known, competitive equilibria of OLG economies may be inefficient even when markets are complete. The competitive equilibrium of a productive economy may not be Pareto optimal because of overaccumulation of capital (Diamond, 1965): in dynamically inefficient economies, the introduction of either a tax-transfer scheme, as a pay as you go social security system, or public debt allows for an increase of welfare.

When uncertainty and market incompleteness are present in the economy, intergenerational transfer policies have also the role of providing risk sharing services. Young agents invest in a risky productive activity to be able to consume when old. In absence of a mutual fund, social security or public debt provide a risk-free way to transfer wealth over time. The same task could as well be undertaken by financial intermediaries, which collect deposits and lend to a large number of firms, thereby perfectly diversifying risk.

This paper studies the efficiency of equilibria in a productive OLG economy with asymmetric information. The model draws on Reichlin and Siconolfi (1996): consumers allocate their disposable wealth between equity shares and (bank) deposits, and firms have access to a random technology, whose input can be financed either by selling shares to consumers or by loans. However, while Reichlin and Siconolfi (1996) consider the effects of adverse selection, ${ }^{1}$ here the economy is affected by ex-post moral hazard due to costly state verification: output is freely observable only by firms, while lenders have to pay some monitoring costs to observe its realization (Townsend, 1979; Williamson, 1987). As in Diamond (1984), costly state verification would allow to derive endogenously the existence of

\footnotetext{
- This paper is based on the first chapter of my Ph.D. Dissertation at Columbia University, New York. I am strongly indebted with Paolo Siconolfi and Pietro Reichlin for many long and precious discussions on this work. I also thank Edmund Phelps, Glenn Hubbard, Roberto Perotti, Nicola Cetorelli and Phillip Jefferson for their useful comments. Financial support from CNR is also gratefully aknowledged. Obviously, I am the only one responsible for any remaining mistakes.

${ }^{1}$ See also Azariadis and Smith, 1993.
} 
financial intermediaries (banks) acting in the economy as delegated monitors of lenders. However, we simply assume that direct lending is not available, and that firms can only borrow from banks. As a result, the cost of monitoring affects the deposits interest rate, which in the model is strictly less than the expected return on shares.

In this framework, the introduction of a tax-transfer scheme (e.g. social security) by the government may be welfare improving even when the economy is dynamically efficient: in fact, when monitoring is too costly, the government could establish a pay as you go social security system (or issue public debt) in order to replace the risk-sharing activity provided by financial intermediaries. The reason for this result is that, in a market economy, social security and bank deposits develop essentially the same role. A benevolent government should decide to use only the instrument whose returns allow for higher consumption opportunities.

Although the economy is affected by asymmetric information and market incompleteness, the inefficiency of competitive equilibria might also be related to additional factors. To analyze these effects, we define a notion of constrained Pareto optimality, that assumes that market incompleteness cannot be eliminated and that the planner is subject to the same information structure of the individuals in the market economy. We show that, in the case of a productive economy, the Constrained Pareto Optimum and the competitive equilibrium are characterized by different allocations of the instruments. The reason is that banks' profit maximizing behaviour is privately efficient, but socially inefficient. In particular, competitive banks' best response to firms declaring bankruptcy is to adopt stochastic verification procedures and a severe punishment for dishonest firms. However, the planner internalizes the fact that firms are owned by consumers and act in the interest of the latter. From a social point of view, it is never optimal to punish firms too harshly. At a Constrained Pareto Optimum, firms are subject to deterministic monitoring when they declare bankruptcy, but the optimal level of punishment is lower than the one chosen by competitive banks. Financial intermediation provided by profit maximizing banks is then responsible for the inefficient outcome of the competitive equilibria. 
The paper is organized as follows. In section 2, we present the model and describe the partial equilibrium financing game played between representative firms and banks. Section 3 deals with general equilibrium and optimal government policies, while Constrained Pareto Optimality is the object of section 4. Conclusions follow.

\section{The model}

\subsection{Agents.}

We study the stationary states of a simple general equilibrium OLG model in which consumers, firms, banks and the government are present. There is a continuum of identical consumers, uniformly distributed on the $[0,1]$ interval. They live for two periods, and population is assumed to be stationary. Each consumer is endowed with W units of a non storable physical good when young, but she likes to consume only when old. When young, consumers are taxed by an amount $\mathrm{T} \in[0, W]$ chosen by the government, who transfers the revenues to currently old people. In the first period of their lives, consumers face only a portfolio problem: they have to choose how to allocate their after-tax endowment (W-T) in two existing assets; more precisely, consumers can buy equity shares by endowing firms with some amount of capital K, or they can buy deposits (D) supplied by financial intermediaries (banks). Equity shares pay a state contingent rate of return, which depends on the outcome of production. We make the following simplifying assumption:

Assumption 1: Each consumer can directly invest in equities of only one firm. ${ }^{2}$

A continuum of ex-ante identical firms is uniformly distributed on the $[0,1]$ interval. Each firm starts with no endowment but has access to a stochastic linear technology such that

\footnotetext{
2 This assumption rules out the possibility for our consumers to diversify their equity holdings. It is an extreme version of a capital market imperfection which prevents consumers to enter an ideal mutual fund able to completely diversify its portfolio (See Reichlin and Siconolfi, 1996).
} 
$\mathrm{X}$ units of capital input return $\alpha \mathrm{X}$ units of output $(\alpha>1)$ with probability q, and 0 with probability 1-q. Investment returns are i.i.d. across firms. When firms are endowed with K units of capital from households ( $\mathrm{K}$ is then the amount of stocks acquired), they can borrow $\mathrm{L}$ $=\mathrm{X}-\mathrm{K}$ from banks. Let $\mathrm{R}$ be the gross rate of interest that firms have to pay back when production is positive; with probability (1-q), instead, the firm goes bankrupt and nothing is due to the bank.

There is a finite number of competitive banks. These are assumed not to be able to buy stocks. Banks collect deposits from households and are the only agents in the economy able to perfectly diversify their portfolio by lending to a large number of firms; for this reason, the law of large numbers guarantees that bank deposits are a safe asset returning a fixed interest rate to consumers.

The economy is characterized by ex-post moral hazard, as banks can observe the realization of the investment process only if they accept to pay a monitoring cost, indicated with letter $\gamma$ and assumed proportional to the loan amount. The lending conditions of the financial contract between banks and firms are studied in the next subsection.

\subsection{The financing game.}

Consider the game between a representative firm and a representative bank. The firm demands a loan, whose cost is set by the bank, and activates its production technology. The outcome of production is private information of the firm; the latter decides whether to report it truthfully to the bank or lie (cheat). The bank receives the report. If the investment project is reported to have been successful, the loan is repaid and the game ends. Instead, if the firm declares bankruptcy, the bank has to choose whether to trust the report, or pay the monitoring cost and obtain full knowledge of the investment outcome. Both players are assumed to be able to randomize on their available pure strategies. We will look for a Nash equilibrium of 
this game, where each player chooses his optimal strategy in order to maximize his expected profits, given the opponent's choice. ${ }^{3}$

In a Nash equilibrium, banks will adopt a monitoring strategy. Otherwise firms have an incentive to report the realization of the "bad state" independently of the effective outcome of production. We will show that, as in Bernanke and Gertler (1989), the optimal monitoring strategy of the banks involves stochastic verification procedures, that is banks monitoring firms declaring bankruptcy with probability less than 1. In order to prove this, it is sufficient to show that a deterministic monitoring strategy can never be part of a Nash equilibrium of this game. The argument runs as follows. Observe that firms never have an incentive to misreport the outcome of production if banks play their proposed (deterministic) equilibrium strategy, as they will always be monitored. Then, firms never misreport. Now, it is obvious that banks are not playing a best response to the proposed equilibrium strategy of the firms, because when they costly monitor reports announcing bad outcomes there is nothing left to recover. Hence, deterministic monitoring is not optimal, ${ }^{4}$ and the financing game does not have any pure-strategy Nash equilibrium. However, the game has a finite number of players and the set of available strategies is finite: this implies that a Nash equilibrium does always exist if one allows for mixed strategies. Let $\mu$ and $\pi$ be respectively the probability that a firm cheats by reporting the bad state when a positive outcome is realized, and the probability

\footnotetext{
${ }^{3}$ Analogously, we could derive the corresponding optimal financial contract by simply applying the Revelation Principle, as in Bernanke and Gertler (1989). This would not change the analysis relevantly, except for the fact that in equilibrium firms will never misreport (this is actually a further assumption: firms are assumed not to misreport whenever they are indifferent between doing this or not). However, in reality, sometime firms do misreport; the formalization in the text takes into account such a possibility.

${ }^{4}$ This is a standard result that can be traced back to Townsend (1979), who pointed out that "stochastic verification procedures can dominate deterministic procedures". Moreover, sometimes stochastic monitoring is also observed in the real world. In Townsend's words: "Stochastic verification procedures are not uncommon. The timing of bank audits by government agencies is somewhat random. Similarly corporations use stochastic procedures in monitoring internal divisions, and it is also said that tax audits by the IRS are determined in part at random."
} 
of banks monitoring when bankruptcy is declared. Moreover, let $\mathrm{V}$ denote the punishment to a firm that does misreport and is monitored by the bank. Then, we have:

Proposition 1 A mixed-strategy Nash equilibrium of the financing game is:

$L^{*}=D^{*}, \quad V^{*}=\alpha(K+L), \quad R^{*}=\alpha, \quad \mu^{*}=(1-q) \gamma L / q[\alpha K+(\alpha-\gamma) L], \quad \pi^{*}=L / K+L$.

Proof Firms will maximize their expected profits by optimally choosing $\mu$ and the desired amount of loans L. Banks will try to maximize their objective function by inelastically supplying their deposits and controlling for $\pi, \mathrm{V}$ and $\mathrm{R}$, the gross interest rate on loans. When choosing the punishment level $\mathrm{V}$, banks are subject to a limited liability constraint:

$\mathrm{V} \leq \alpha(\mathrm{K}+\mathrm{L})$, meaning that the punishment cannot exceed the outcome of production.

Let $\Pi$ be profits from production. The firms' problem is formally written as follows:

FP: $\quad \underset{L, \mu}{\operatorname{Max}} E \Pi=q[\alpha(K+L)-(1-\mu) R L-\mu \pi V]$

In the good state, firms realize output, pay back the loan plus the charged interest if they do not cheat, and are punished by an amount $\mathrm{V}$ in the case they cheat but are monitored (this happens with probability $\mu \pi)$.

In this game banks are price takers on the deposits side. ${ }^{5}$ Thus, the banks' problem is:

BP:

$$
\underset{\pi, R V}{\operatorname{Max}} E P=q R L(1-\mu)+q \quad(V-L)-(1-q) \quad L-I D
$$

$$
\text { s.t. } \quad V \leq(K+L) \quad \text { and } \quad L \leq D
$$

where EP denotes banks' expected profits, and I the gross interest rate due on deposits. 
with probability $\mu$ ), banks recover $V$ only when they monitor (with probability $\pi$ ); in this case, they also have to pay the cost of state verification.

Monotonicity of EP with respect to $\mathrm{R}$ and $\mathrm{V}$ implies that these variables are set at their maximum levels. Then, $\mathrm{V}^{*}=\alpha(\mathrm{K}+\mathrm{L})$. This allows to rewrite the objective functions in problems $\mathrm{FP}$ and $\mathrm{BP}$ as
(1) $E \Pi=q[\alpha K+(\alpha-R) L+\mu[R L-\pi \alpha(K+L)]]$
(2) $E P=q R L(1-\mu)+\pi[q \mu \alpha(K+L)-q \mu \gamma L-(1-q) \gamma L]-I D$

In order to optimally select $\mu$ and $\pi$, maximization of (1) and (2) implies that
(3) $\mu^{*}= \begin{cases}0 & \text { if } J<0 \\ {[0,1]} & \text { if } J=0 \\ 1 & \text { if } J>0\end{cases}$
where $J=R L-\pi \alpha(K+L)^{6}$

and
(4) $\pi^{*}= \begin{cases}0 & \text { if } H<0 \\ {[0,1]} & \text { if } H=0 \\ 1 & \text { if } H>0\end{cases}$
with $\quad H=q \mu[\alpha K+(\alpha-\gamma L)]-(1-q) \gamma L^{7}$

The only intersection of the above reaction functions implies $\mu^{*} \in(0,1)$ and $\pi^{*} \in(0,1) .8$ Hence, from $\mathrm{J}=0$ and $\mathrm{H}=0$ we obtain

$(5) \pi *=\frac{R L}{\alpha(K+L)}$

and

(6) $\mu *=\frac{(1-q) \gamma L}{q[\alpha K+(\alpha-\gamma) L]}$

\footnotetext{
${ }^{6} \mathrm{~J}$ can be interpreted as the difference between the cost of being honest (LR) and the expected cost of cheating $(\pi \alpha(\mathrm{K}+\mathrm{L}))$.

${ }^{7} \mathrm{H}$ is the difference between the expected revenues and the cost of monitoring.

${ }^{8}$ One should notice that this result was already obtained in the informal reasoning preeceding Proposition 1.
} 
The demand for loans is

(7) $\mathrm{L}^{*}= \begin{cases}0 & \text { if } \alpha<R \\ \in[0, \infty] & \text { if } \alpha=R \\ \infty & \text { if } \alpha>R\end{cases}$

From (7), it is clear that the maximum level of $\mathrm{R}$ that banks can set is $\mathrm{R}^{*}=\alpha$. Hence, we also have $\pi^{*}=L /(K+L)$. Since the demand for loans when $\mathrm{R}^{*}=\alpha$ is not determined, the model is closed by letting equilibrium loans be equal to the amount supplied. Then, $\mathrm{L}^{*}=$ D.

In equilibrium banks monitor randomly. This creates an opportunity for firms to misreport good outcomes with a positive probability. Moreover, the optimal monitoring probability increases with the amount of the loan and decreases with K. Analogously, straightforward differentiation of (6) shows that $\mu^{*}$ is increasing in $\mathrm{L}$ and decreasing in $\mathrm{K}$.

\section{General Equilibrium.}

\subsection{Existence of a competitive equilibrium.}

Consumers save in their first period of life and consume when old. Consumption tomorrow is a stochastic variable depending on the realized returns of the first period saving choice. We assume that preferences of our consumers are continuous and strictly monotone. More precisely, we also require that the following holds:

Assumption 2: Preferences are represented by a continuous utility function $\mathrm{u}($.$) which is twice$ continuously differentiable, strictly increasing and strictly concave, and satisfies

$$
\lim _{c \rightarrow 0} u^{\prime}(c)=\infty, \quad \lim _{c \rightarrow \infty} u^{\prime}(c)=0
$$


Let $\tilde{z}$ be the stochastic gross return on stocks and W-T the after tax endowment of units of the non storable good. Our consumers face the standard problem of

$$
\begin{array}{ll}
\text { CP: } & \operatorname{Max}_{K, D} E u(\widetilde{c}) \\
\text { s.t. } & K+D=W-T \\
& \tilde{c}=T+I D+\widetilde{z} K \\
& K, D \geq 0
\end{array}
$$

whose first order condition is

$$
\begin{aligned}
& E\left[u^{\prime}(\tilde{c})(I-\tilde{z})\right] D \leq 0, \\
& \text { with } E\left[u^{\prime}(\tilde{c})(I-\tilde{z})\right]=0 \text { if } D>0
\end{aligned}
$$

When choosing D optimally, consumers take $\mathrm{I}$ and $\tilde{z}$ as parametric: $\tilde{z}$ has the following distribution:

$$
\tilde{z}= \begin{cases}0 & \text { w.p. }(1-q)+q \mu \pi \\ \alpha & \text { w.p. } q(1-\mu) \\ \alpha\left(\frac{K+D}{K}\right) & \text { w.p. } q \mu(1-\pi)\end{cases}
$$

In fact, buying stocks pays back nothing if the bad state of the world is realized or if the firm cheats but is monitored: the cumulative probability of this event is $(1-q)+q \mu \pi$. With probability $\mathrm{q}(1-\mu)$ instead, stocks pay back exactly $\alpha$, while the most profitable gross return is $\alpha(\mathrm{K}+\mathrm{D}) / \mathrm{K}$, whose probability is equal to $\mathrm{q} \mu(1-\pi)$. The expected gross return on stocks is $\alpha q \cdot 9$

Free entry in the banking sector requires the equilibrium level of I being determined by the zero profit condition. In equilibrium,

\footnotetext{
${ }^{9}$ This can be derived after substituting for the optimal probability choices derived in section 2 .
} 
(9) $I=\alpha q\left[1-\frac{(1-q) \gamma D}{q[\alpha K+(\alpha-\gamma) D]}\right]$

Since our consumers preferences satisfy Assumption 2, $\mathrm{E}(\tilde{z})>\mathrm{I}$ is a necessary condition for an interior solution (K, D) >>0: (9) guarantees that this condition holds.

Definition A stationary equilibrium for the model economy is an array of rates of return $(\mathrm{I}, \tilde{z})$, probabilities $(\mu, \pi)$, portfolio allocation $(\mathrm{K}, \mathrm{D})$ and loans $\mathrm{L}$ such that:

i) loans are equal to deposits; ii) banks have zero expected profits; iii) consumers maximize expected utilities and firms expected profits; iv) the goods market clears.

Proposition 2 For any $\mathrm{T} \in[0, \mathrm{~W})$, there exists a stationary equilibrium for the competitive productive economy $(\alpha q>1)$, with $(\mathrm{K}, \mathrm{D})>>0$.

Proof Let $\mathrm{F}(\mathrm{D},)=.\mathrm{E}\left[\mathrm{u}^{\prime}[\mathrm{T}+\tilde{z}(\mathrm{~W}-\mathrm{T}-\mathrm{D})+\mathrm{ID}](\mathrm{I}-\tilde{z})\right] . \mathrm{F}$ is continuous in D. From (8), a competitive equilibrium is either $\mathrm{D}^{*}=0, \mathrm{~F}(0,) \leq$.0 , or $\mathrm{D}^{*}>0$ and $\mathrm{F}\left(\mathrm{D}^{*},.\right)=0$. Let $\mathrm{T} \in[0, \mathrm{~W})$. If $\mathrm{D}=0, \mathrm{~K}=\mathrm{W}-\mathrm{T}$, and future consumption is equal to $\mathrm{T}$ with probability (1-q), and to $\mathrm{T}+$ $\alpha(\mathrm{W}-\mathrm{T})$ with probability q. Then, $\mathrm{F}(0,)=.[(1-\mathrm{q})] \mathrm{I} \mathrm{u}^{\prime}(\mathrm{T})-\mathrm{q}(\alpha-\mathrm{I}) \mathrm{u}^{\prime}(\mathrm{T}+\alpha(\mathrm{W}-\mathrm{T}))>$ $>\mathrm{u}^{\prime}(\mathrm{T})[(1-\mathrm{q}) \mathrm{I}-\mathrm{q}(\alpha-\mathrm{I})]=0$.

If $\mathrm{D}=\mathrm{W}-\mathrm{T}, \mathrm{K}=0$ and $\mathrm{F}(\mathrm{W}-\mathrm{T},)=.\mathrm{u}^{\prime}[\mathrm{T}+\mathrm{I}(\mathrm{W}-\mathrm{T})](\mathrm{I}-\mathrm{E}(\tilde{z}))<0$. By continuity of $\mathrm{F}($.$) there$ exists a $\left(\mathrm{K}^{*}, \mathrm{D}^{*}\right)>>0$, such that $\mathrm{F}\left(\mathrm{K}^{*}, \mathrm{D}^{*}\right)=0 .\left(\mathrm{K}^{*}, \mathrm{D}^{*}\right)$ is the competitive equilibrium.

Equilibria of productive economies $(\alpha q>1)$ are characterized by the contemporaneous existence of financial intermediation and equity investment. Financial intermediation provides risk sharing services to risk averse consumers. However, costly state verification implies that banks do not monitor with probability equal to one firms reporting bad outcomes. If a firm misreports a positive outcome and it is not monitored, its shareholders receive a high return. Equity investment will then also be positive. 


\subsection{Optimal policies.}

In this economy the government can optimally establish the amount of social security $\mathrm{T}$.

Because of market incompleteness, risk aversion and costly monitoring, the optimal policy produces results which deviate from the standard Samuelson (1958) and Diamond (1965) conclusions. In particular, in our model it could be welfare improving to introduce social security (or issue public debt) even when the economy is dynamically efficient, that is when the expected return on capital is greater than population growth $(E(\tilde{z})=\alpha q>1) .{ }^{10}$ The reason is that financial intermediation and social security develop essentially the same role, that is they provide risk sharing services to risk averse consumers who cannot perfectly diversify their equity holdings. 11

\section{Constrained Pareto Optimality.}

Competitive equilibria of OLG economies may be subject to different sources of inefficiency: they can be dynamically inefficient because of overaccumulation of capital, or inefficient because of lack of complete portfolio diversification in a context of uncertainty at the

\footnotetext{
${ }^{10}$ See Azariadis and Smith (1993) and Reichlin and Siconolfi (1996) for similar results in the context of models with adverse selection. In particular, Reichlin and Siconolfi (1996) found that it is also possible to obtain different conclusions from the ones obtained under perfect information even when the economy is dynamically inefficient. In fact, they can show that in a credit-rationing equilibrium a la Stiglitz-Weiss (1981) of an OLG stationary economy, the introduction of a new asset (debt, social security or outside money) could be welfare reducing when the rate of return on capital is lower than population growth.

${ }^{11}$ Define $\lambda=\frac{\alpha(1-q) \gamma D}{\alpha K+(\alpha-\gamma) D}$. If the economy is dynamically efficient but $\alpha q<1+\lambda$, then $\mathrm{I}<1$, and the return on deposits is lower than the one on $T$. Hence, if $\alpha q=1+\varepsilon$, with $\varepsilon$ arbitrarily small, provided that consumers are sufficiently risk averse, they will be strictly better-off by consuming $\mathrm{T}^{*}=\mathrm{W}$ with probability equal to one, with respect to any other consumption allocation resulting from a portfolio of two safe assets $(T, D)$ with returns respectively equal to 1 and $\mathrm{I}<1$, and a risky asset $(\mathrm{K})$ with expected return $1+\varepsilon$. When $\alpha q>1+\lambda$, equation (9) implies that the safe gross return on deposits is strictly greater than 1. In this case, deposits strictly dominate $\mathrm{T}$, and social security should be optimally set to zero; financial intermediation and equity investment will instead be active. Clearly this case, for given values of the parameters $\alpha$ and q, is more likely the lower the monitoring cost $\gamma$.
} 
individual level: in this second case, once market incompleteness is eliminated, equilibria turn out to be Pareto optimal.

When economies are also subject to asymmetric information, the inefficiency of market clearing allocations is usually related to the agents' behaviour in a way which can be distinguished from market incompleteness (Azariadis and Smith, 1993). Hence, even by assuming that market incompleteness cannot be removed, one could try to establish whether market equilibria satisfy a weaker notion of efficiency than Pareto optimality. This notion will be called Constrained Pareto Optimality, and it is derived under the assumption that the planner cannot introduce additional assets and is subject to the same information structure of the individuals. Therefore, we give the following

Definition A Constrained Pareto Optimum is an allocation (K,D,T) such that the expected utility of the representative consumer is maximized, subject to the resource allocation constraint, individual budget constraints, and the informative constraint that the planner cannot freely observe outcomes of production activity.

Notice that when $\alpha \mathrm{q} \leq 1$, the Pareto efficient allocation (and a fortiori the Constrained Pareto Optimum) is trivially $\mathrm{T}^{*}=\mathrm{W}$, which corresponds to the optimal policy in the market economy. Henceforth, we limit our attention to dynamically efficient economies where $\alpha q>$ 1. The social planner can try to achieve his or her target by controlling the portfolio allocation $(\mathrm{K}, \mathrm{D}, \mathrm{T})$, the supply of loans $(\mathrm{L})$, the interest rates on loans and deposits $(\mathrm{R}, \mathrm{I})$, the punishment to the firm when this is caught cheating $(\mathrm{V})$, and the probability $(\pi)$ of monitoring when bad outcomes are reported. Moreover, contrary to the representative consumer, the planner internalizes the effect of his (her) savings and monitoring choices on the assets' returns. The planner's problem can then be written as follows: 
$\underset{K, D, T, L, \pi, V, R, I}{\operatorname{Max}} \operatorname{EU}(\tilde{c})$

(PP)

$$
\begin{array}{ll}
\text { s.t. } \quad W & =T+K+L \\
\tilde{c} & =\tilde{z} K+I L+T \\
V & \leq \alpha(K+L) \\
L & \leq D
\end{array}
$$

and the relevant non-negativity constraints.

Obviously, $\mathrm{L}=\mathrm{D}$ since in the model there is no other asset in which banks' liabilities can be invested. The planner has also to consider two additional constraints. The first is due to the fact that $\mu$ is optimally chosen by firms, that is

10) $\mu^{*}= \begin{cases}0 & \text { if } R L<\pi V \\ {[0,1]} & \text { if } R L=\pi V \\ 1 & \text { if } R L>\pi V\end{cases}$

The second is the resource constraint, establishing that the sum of aggregate (average) investment and consumption has to be equal to aggregate production plus aggregate endowments minus the amount of resources destroyed in the monitoring activity. Since there is a continuum of individuals, by the law of large numbers, the resource constraint is

(11) $E(\tilde{c})+(K+L)=W+\alpha q(K+L)-\pi \gamma L$

Observe that (11) uniquely determines I. In fact, since

(12) $\mathrm{E}(\tilde{c})=\mathrm{T}+\mathrm{IL}+\mathrm{E}(\tilde{z}) \mathrm{K}$, and

(13) $\mathrm{E}(\tilde{z}) \mathrm{K}=\alpha \mathrm{q}(\mathrm{K}+\mathrm{L})-\mathrm{q} \mu \pi \mathrm{V}-\mathrm{q}(1-\mu) \mathrm{RL}$,

one easily obtains

(14) $I L=q(1-\mu) R L+q \mu \pi V-\pi \gamma L$. 
The other assets' returns are: T pays back 1 (gross) for sure, while capital investment gross returns are

$$
\tilde{z} \mathrm{~K}= \begin{cases}0 & w \cdot p \cdot 1-q \\ \alpha(K+L)-V & \text { w.p. } q \mu \pi \\ \alpha(K+L)-R L & w \cdot p \cdot q(1-\mu) \\ \alpha(K+L) & w \cdot p \cdot q \mu(1-\pi)\end{cases}
$$

Hence, consumption opportunities in the four states of nature are:

$$
\begin{array}{ll}
c_{1}=T+I L & \text { w.p. } 1-q \\
c_{2}=T+I L+\alpha(K+L)-V & \text { w.p. } q \mu \pi \\
c_{3}=T+I L+\alpha(K+L)-R L & w \cdot p \cdot q(1-\mu) \\
c_{4}=T+I L+\alpha(K+L) & \text { w.p. } q \mu(1-\pi)
\end{array}
$$

Claim 1 For any $\mu^{*} \in[0,1)$, the expected utility of consumers is strictly increasing in $\mathrm{R}$. Proof If $\mu^{*}=1, \operatorname{EU}(\tilde{c})$ is not affected by R. Now, assume $\mu^{*} \in[0,1)$.

Then $\mathrm{IL}=\mathrm{qRL}-\pi \gamma \mathrm{L} . \quad$ By simple differentiation, $\mathrm{d}[E U(\tilde{c})] / \mathrm{d} R>0$.

Since $\mathrm{d}[E U(\tilde{c})] / \mathrm{d} R \geq 0 \quad\left(>0\right.$ for $\left.\mu^{*} \neq 1\right)$, the optimal value of $\mathrm{R}$ is greater or equal to $\alpha$. However, if $\mathrm{R}>\alpha$, the demand for loans drops to zero since firms are profit maximizers. Hence, Claim 1 implies $\mathrm{R}^{*}=\alpha$.

Claim 2 Let $\gamma$ be arbitrary small. Then, at a Constrained Pareto Optimum, $V *=\alpha L$ and $\pi^{*}$ $=1$.

Proof Suppose that $\gamma=0$, and let $\mu^{*} \in(0,1) .{ }^{12}$ Hence, from equation (10) and Claim 1,

\footnotetext{
${ }^{12}$ This is without loss of generality. A similar argument can be applied for $\mu^{*}=0$, or for $\mu^{*}=1$.
} 
$\pi \mathrm{V}=\alpha \mathrm{L}$. Moreover, a change in $\mathrm{V}$ only affects consumption opportunities $\mathrm{c}_{2}$ and $\mathrm{c}_{4}$, as well as their probabilities. Hence, the optimal choice of $\mathrm{V}$ should maximize the expected utility of consumption in these two states. Observe that $c_{2}=c_{4}-V$. The problem can then be written as

$$
\underset{V}{\operatorname{Max}} \frac{\alpha L}{V} U\left(c_{4}-V\right)+\left(1-\frac{\alpha L}{V}\right) U\left(c_{4}\right)
$$

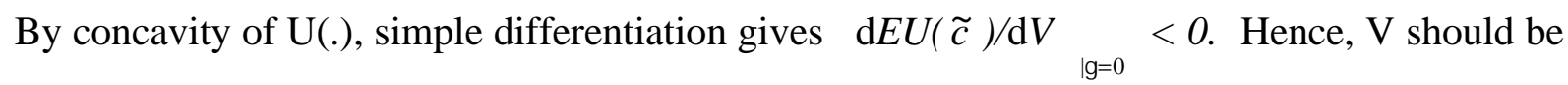
set at its lower feasible bound. Since $\pi \leq 1, \mathrm{~V}^{*}=\alpha \mathrm{L}$, and $\pi^{*}=1$. Since $\mathrm{d} E U(\tilde{c}) / \mathrm{d} V$ is a continuous map of the cost $\gamma$, and since $\mathrm{d} E U(\tilde{c}) / \mathrm{d} V_{\gamma=0}<0$, for $\gamma$ small enough, the inequality holds true.

Notice that, independently of $\mu$, consumption opportunities can be rewritten as

$$
\begin{array}{ll}
c_{1}=T+I L & \text { w.p. } 1-q \\
c_{2}=T+I L+\alpha K & \text { w.p. } q
\end{array}
$$

where $I=\alpha q-\gamma$. Therefore:

Proposition 3 If $\gamma$ is small, and $\alpha q-\gamma>1$, the Constrained Pareto Optimum calls for no tax-transfer policy $\left(T^{*}=0\right)$ and strictly positive levels of equity financing and bank lending $\left(K^{*}, L^{*}>>0\right)$. Moreover, $R^{*}=\alpha, V^{*}=\alpha L^{*}$ and $\pi^{*}=1$.

Proof Obvious.

Corollary If $\alpha q-\gamma<1$, the Constrained Pareto Optimum is instead $L^{*}=0, \quad\left(K^{*}, T^{*}\right)>>0$.

Remark 1 A Constrained Pareto Optimum is characterized by deterministic monitoring, at least for small monitoring costs. The distortion in the market economy is induced by banks behaving as profit maximizers. Competitive banks monitor firms declaring 
bankruptcy with probability less than one, and they punish cheating by setting $\mathrm{V}=\alpha(\mathrm{K}+\mathrm{L})$. However, firms are owned by consumers and act in their interest. From the consumers' point of view, deterministic monitoring dominates any stochastic verification procedure, while for the banks only the latter is supported by profit maximization. This affects the returns offered by the assets and the incentives to choose the optimal portfolio allocation. The banks' profit maximizing behaviour is then responsible for the inefficient outcome of the competitive equilibria.

Remark 2 Even though, when monitoring is not too costly, market outcomes and the Constrained Pareto Optimum are both characterized by the active use of the same instruments ( $\mathrm{L}$ and $\mathrm{K})$, the equilibrium allocations are different. Moreover, there is no optimal policy in a market economy which can induce banks to monitor with probability equal to one when bankruptcy is declared. Hence, this kind of market equilibria inefficiency cannot be eliminated by using traditional macreoconomic policies. In order to restore the efficient outcome, the policymaker should act as a regulator of the microstructure of private contracts. 13

\section{Conclusions.}

This paper investigates the efficiency properties of a productive OLG model subject to expost moral hazard in the form of costly state verification. Competitive equilibria are characterized by banks adopting stochastic monitoring of bankruptcy reports, and firms having an incentive to lie. The optimal policy of the government introduces a social security system under more general conditions than in the perfect information case. We show that market outcomes can fail to achieve even a weaker notion of efficiency than Pareto optimality, which is derived under the hypothesis that market incompleteness cannot be eliminated. This result depends on the role of profit maximizing financial intermediaries:

\footnotetext{
${ }^{13}$ In our example, the policy maker should require the lending contract to be designed so as to include deterministic monitoring of bankruptcy reports.
} 
these adopt stochastic verification procedures which are privately optimal, but socially inefficient in an economy with private ownership.

\section{References}

Azariadis, C. and Smith B. (1993): 'Adverse selection in the overlapping generations model: the case of pure exchange', Journal of Economic Theory, 60, 277-305.

Bernanke, B. and Gertler, M. (1989): 'Agency costs, net worth and business fluctuations', American Economic Review, 79, 14-31.

Diamond, P. (1965): 'National debt in a neoclassical growth model', American Economic Review, 55, 1026-50.

Diamond, D. (1984): 'Financial intermediation and delegated monitoring', Review of Economic Studies, 51, 393-417.

Reichlin, P. and Siconolfi, P. (1996): 'The role of social security in an economy with asymmetric information and financial intermediaries', Journal of Public Economics, 60, 15375.

Samuelson, P. (1958): 'An exact consumption loan model of interest with or without the social contrivance of money', Journal of Political Economy, 66, 467-82

Stiglitz J. and A. Weiss (1981): "Credit rationing in markets with imperfect information", American Economic Review, 71, 393-410.

Townsend, R. (1979): 'Optimal contracts and competitive markets with costly state verifications', Journal of Economic Theory, 21, 265-93.

Williamson, S. (1987): 'Costly monitoring, loan contracts, and equilibrium credit rationing', Quarterly Journal of Economics, 52, 135-45. 